\section{Replies to Shein, Voigt and Chapman}

\author{
Daniel Halliday
}

I'd like to thank all three commentators for their careful discussion of my proposals. I'll begin with David Shein, who makes two very important points. First, he raises the problem of black markets, which received only a passing mention in the original piece. Generally speaking, black markets can be expected to operate more readily, and on a larger scale, given opportunities for arbitrage: Much depends on how easy it is for illicit sellers to obtain the commodity at prices lower than those at which they can sell it on, given what other costs they incur in the process, such as those associated with transportation and storage. (Opportunities for arbitrage can be enhanced by certain ways of designing licences-see the discussion of Chapman's proposal below.) Shein is right to distinguish between a black market in actual tobacco products, and a black market in licences granting a legal right to purchase such products. As he points out, a market in stolen or forged licences would be likely to carry much lower storage and transportation costs than those associated with tobacco itself. This is an astute observation. But it would be hasty to assume that illegal trade in licences would be easy to get off the ground. Illicit selling would have to rely on forgery and/or the ability to modify licences so as to change the identity of their bearer. Accordingly, perhaps the best response to Shein's concern is that licence design can likely profit from ongoing progress in anticounterfeiting technology, such as that used to combat black markets in other documents that are intended to be non-transferable across users, such as passports. As these technologies continue to improve, it is likely that a black market in licences will become gradually less viable.

Shein's second concern is more philosophical: As I acknowledged in the original piece, one objection to a smoker's licence is that it will discriminate against low-income smokers. Assuming that the price of a licence remains the same for richer and poorer consumers, the 'real' burden of payment will be higher, the poorer the consumer. This is a familiar problem of regressive taxation, common to consumption

Correspondence to Dr Daniel Halliday, 1Philosophy, University of Melbourne, East Wing, Old Quad Building, Melbourne, VIC 3010, Australia;

daniel.halliday@unimelb.edu.au taxes in general, including status quo sales taxes on cigarettes. Insofar as the task is to find some moral improvement on the status quo, it may be enough to show how a smoker's licence may be less discriminatory than a sales tax. The article that features in this issue was first published online in 2013. I've argued more recently, elsewhere, that licences may be designed such that lowincome consumers are given a rebate of at least part of what they paid for the licence. ${ }^{1}$ This could be done quite easily if consumers submitted their tax identity when purchasing a licence. It would then be possible to identify which licence holders have the lowest incomes, and issue rebates accordingly. Because consumers do not know in advance whether they are among the poorest licensees, a rebate need not undermine the deterrent effect of the upfront cost. Accordingly, licence design can correct (somewhat) for the otherwise discriminatory nature of consumption tax in ways that sales tax cannot. This is not to say that the problem can be wholly solved, and worries about discrimination should remain a central preoccupation of most attempts to defend the use of consumption taxes.

Kristin Voigt is wary of my claim that 'smoking is just bad'. That's fair enough: The claim is rather provocative and could use more defence. The more principled point that Voigt wishes to press is that 'we need a clearer sense of the 'ideal' goal that should be guiding tobacco control'. There may be some indeterminacy as to what sort of outcome is 'ideal' when it comes to tobacco consumption. One view is that an ideal world is one in which nobody smokes. But why is such a world superior, say, to a world in which healthcare has become so advanced that any negative health outcomes associated with smoking could be cured immediately at very low cost? The latter scenario may ultimately count as the more ideal, particularly if smoking has at least some benefits.

The right strategy for dealing with such difficulties may depend on exactly how one interprets the ideal/non-ideal distinction in political philosophy. One view is that non-ideal theory doesn't really need a detailed account of what ideal scenario is meant to count as its 'destination'. It may be enough to work with an accurate account of what's wrong with the status quo as a departure point. This allows us to say that there may be no determinate answer as to what the ideal scenario might be, given that just about any downside of smoking could be idealised away. There is wide agreement that, so far as the status quo is concerned, tobacco cessation is a significant improvement. To the extent that one can argue for an ideal scenario in which smoking endures without the bad features it currently carries in the real world, one might view a smoking licence (or any other cessation technique) as an interim device that might be retained up until such point at which smoking can occur safely. As such, different views about the ideal goal of tobacco cessation policy may disagree as to whether a smoking licence might be a temporary or interim measure, or else something more permanent. But the case for a licence, as a way of improving on the current situation, may remain strong across quite different views about whether it's really right to say that smoking is 'just bad'.

Simon Chapman's commentary, by far the longest of the three, draws on his expertise as perhaps the foremost researcher on tobacco licencing (and related aspects of tobacco policy) over the last decade or so. His main complaint is directed at my suggestion that a tobacco licence might wholly replace the status quo sales tax, levied at the point of purchase. This contrasts with Chapman's preferred approach of running a sales tax and a smoking licence simultaneously. This preference of Chapman's is strong: He claims that 'the idea of the licence replacing taxation is a large straw man' and 'quite bizarre'. He does not, however, offer much argument as to why the retention of a sales tax is so important or valuable. He does observe that a licence-only proposal is 'not under serious (nor indeed any) debate outside of Halliday's paper'. But observations of this sort do not carry any force unless they can be accounted for by argued objections.

The only theoretical objection that I can see in Chapman's response is that a licence, used on its own without sales taxes, would simply be too expensive for smokers to purchase. My own suggestion was that a licence should be priced at the same level as the amount of tax that would be levied on the number of cigarettes that the licence allows its holder to purchase. One reason for selecting this figure to ensure that a switch from sales taxes to licencing could not be accused of involving an increase in taxation-cigarettes would still be taxed at the same rate, with the licence serving to shift the financial burden 'upfront', as emphasised by authors such as Le Grand. It's fair to say that a licence risks greater unpopularity if it is perceived 
as a way of making smokers pay more per cigarette than the sales taxes it might replace. Keeping the per unit rate of taxation the same may secure some immunity from the objection that a licence is really a ruse to increase government revenues, or 'stealth tax'. Chapman claims that it is 'fanciful' to suggest that low-income smokers will be able to access the amount required to buy a licence each year at this price. I am not sure what sort of criticism he intends to convey. For one thing, lowincome smokers already do access such an amount each year if they purchase an average number of packs per year. Of course, some low-income smokers purchase less than the current average number of cigarettes annually. On my proposal (but not on Chapman's) their licence would therefore take longer to expire, meaning that their expenditure per year would actually be lower than that of average to heavy smokers. Of course, as I acknowledged in the original article, lowincome smokers may find it very hard to access a year's worth of cigarette expenditure all at once, as would be required if licences were to replace sales taxes. But this fact reflects part of the very purpose of a licence: By making smokers pay 'upfront', smoking is deterred. If it turns out that low-income smokers cannot afford a licence, or are forced to smoke less due to difficulties in affording a replacement licence, then this may be a feature of the proposal rather than a devastating objection. It may be that by invoking the case of low-income smokers, Chapman is implicitly making the objection about discrimination spelled out more fully by Shein and myself, in which case I refer the reader to my earlier remarks above. The question of how to price a smoker's licence is a difficult question, but not difficult in ways that obviously show that sales taxes need to be retained alongside whatever sort of licence might be implemented.

Doing away with sales taxes may carry some advantages that Chapman does not anticipate. First, there is the possibility that licences are less discriminatory than standard sales taxes, something that can be pursued through aspects of licence design that are not realisable elements of any sales tax design (see my response to Shein, above). Another advantage may be that any simultaneous implementation of sales taxes and a licence is vulnerable to certain forms of political rhetoric. One effective, though fallacious, source of opposition is the complaint of 'double taxation'. This has been used effectively to suppress the taxation of inherited wealth, where it has been said that taxation is unjust because what's taxed has already been taxed before (eg, through income tax). ${ }^{2}{ }^{3}$ Chapman himself notes that tobacco reform faces serious political obstacles. There is plenty of lobbying power behind efforts to destroy policy reforms aimed at reducing tobacco consumption. As I explained in the original piece, considerations of political feasibility may favour implementing a smoker's licence in ways that avoid perception of it being 'yet another tax'. Simultaneous repeal of sales taxes may achieve this. It would be speculative to make any really strong claim about exactly what sort of political narrative would emerge from the implementation of a smoker's licence and what sort of impact such a narrative might have. But we should not dismiss the power of antitaxation rhetoric when considering policies that apparently multiply the number of taxes even without increasing the overall tax burden on citizens.

Chapman's comments draw attention to aspects of his positive position, which are worthy of some comment. In the original article, I grouped Chapman's position along with Le Grand's under the 'temporal' model. Chapman protests about this, and he's right to note that some aspects of his view distinguish it usefully from Le Grand's. Still, Chapman's proposal requires that licences 'would need to be renewed each year', even for consumers who have not maxed out the number of cigarettes that their licence entitles them to purchase within that period. This is a temporal expiration condition. As I explained in the original article, licences that expire after a certain amount of time are open to worries about smokers honouring sunk costs. Chapman's proposal contains various nuances that could make a difference to this sort of problem, particularly his inclusion of a maximum daily limit whose level can be fixed at alternative thresholds by giving smokers a choice between different types of licences. The ability of consumers to set different limits creates opportunities for arbitrage on a black market: Consumers may select daily limits higher than their own demand for cigarette consumption, for the purposes of selling cigarettes to consumers who are maxed out, or to those who do not hold licences, such as minors. Chapman's requirement that licences expire after 12 months remains a substantive difference separating his proposal from any licence that expires when and only when some specified quantity of cigarettes has been purchased. Chapmen's model thus remains 'temporal' in a very straightforward sense that a licence must be renewed once a certain period of time has elapsed since its purchase. I stand by the claim that defining expiration in this temporal way has implications not shared by alternative models, and there is nothing implausible or inaccurate about exploring the advantages of doing things differently.

I accept that there's every possibility that a combination of licencing and sales taxes could prove more plausible, at least in terms of effectiveness, than a licence used by itself. But, if so, then this will be due to the facts about how smokers variously respond to different sorts of cessation policies. It will not be due to any supposed conceptual mistake about having a licence replace sales taxes altogether. It remains unclear why Chapman is so opposed to dispensing with a point-of-purchase sales tax. His own licence design doesn't require sales taxes to remain. His version of the smoking licence could yet prove, on balance, to be the best available, though I continue to emphasise the advantages of having licences expire only when some absolute quantity of cigarettes has been purchased. It may be that there is little precedent for considering licences as outright replacements for sales taxes. But proposals should stand and fall on their merits, not their historical (un)popularity. A position that happens to have been largely unexamined, is not thereby a straw man, particularly when it's offered as an alternative to proposals that have their own problems.

\section{Competing interests None declared.}

Provenance and peer review Commissioned; internally peer reviewed.

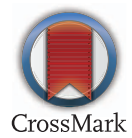

To cite Halliday D. J Med Ethics 2016;42:291-292.

Received 29 February 2016

Accepted 2 March 2016

Published Online First 5 April 2016

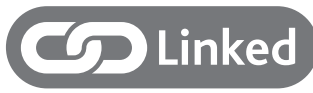

http://dx.doi.org/10.1136/medethics-2013-101347

J Med Ethics 2016:42:291-292.

doi:10.1136/medethics-2016-103505

\section{REFERENCES}

1 Halliday D. Egaitarianism and consumption tax. In: Gaisbauer H, Schweiger G, Sedmak C, eds. Philosophical explorations of justice and taxation. Springer, 2015:119-34.

2 Murphy L, Nagel T. The Myth of Ownership: Taxes and Justice. Oxford University Press, 2002:143-4.

3 Graetz M, Shapiro I. Death by a thousand cuts: the fight over taxing inherited wealth. Princeton University Press, 2005. 